\title{
Supercapacitors: Properties and Applications
}

\author{
LIBICH, J.; MÁCA, J.; VONDRÁK, J.; ČECH, O.; SEDLAŘÍKOVÁ, M.
}

Journal of Energy Storage

2018, vol. 17 iss. 1 , pp. 224-227

ISSN : 2352-152X

DOl: http://dx.doi.org/10.1016/j.est.2018.03.012

Accepted manuscript

(C) 2018. This manuscript version is made available under the CC-BY-NC-ND 4.0 license (http://creativecommons.org/licenses/by-nc-nd/4.0/), doi: 10.1016/j.est.2018.03.012 Final version available from https://www.sciencedirect.com/science/article/pii/S2352152X18301634 


\title{
Supercapacitors: Properties and Applications
}

\author{
Jiří Libich*, Josef Máca, Jiří Vondrák, Ondřej Čech and Marie Sedlaříková \\ Department of Electrical and Electronic Technology, Faculty of Electrical Engineering and \\ Communication, Brno University of Technology, 61600 Brno, Czech Republic
}

\begin{abstract}
Energy accumulation and storage is one of the most important topics in our times. This paper presents the topic of supercapacitors (SC) as energy storage devices. Supercapacitors represent the alternative to common electrochemical batteries, mainly to widely spread lithium-ion batteries. By physical mechanism and operation principle, supercapacitors are closer to batteries than to capacitors. Their properties are somewhere between batteries and capacitors. They are able to quickly accommodate large amounts of energy (smaller than in the case of batteries - lower energy density from weight and volume point of view) and their charging response is slower than in the case of ceramic capacitors. The most common type of supercapacitors is electrical double layer capacitor (EDLC). Other types of supercapacitors are lithium-ion hybrid supercapacitors and pseudo-supercapacitors. The EDLC type is using a dielectric layer on the electrode - electrolyte interphase to storage of the energy. It uses an electrostatic mechanism of energy storage. The other two types of supercapacitors operate with electrochemical redox reactions and the energy is stored in chemical bonds of chemical materials. This paper provides a brief introduction to the supercapacitor field of knowledge.
\end{abstract}

\section{Keywords}

Supercapacitor, Energy, Storage, Pseudo-supercapacitor, Hybrid-supercapacitor, Lithium

\section{Highlights}

- Supercapacitors have interesting properties in relation to storing electric energy, as an alternative to batteries.

- Supercapacitors can handle very high current rates.

- Supercapacitors have low energy density to unit weight and volume.

- The price per unit of energy $(\mathrm{kWh})$ is extremely high.

\footnotetext{
* Correspondence author: Jiř́i Libich

e-mail address: libich@feec.vutbr.cz

Department of Electrical and Electronic Technology,

Brno University of Technology
} 


\section{Introduction}

Limited sources of fossil fuels along with growing population and technology development put the mankind in front of an energy problem. Increasing pollution forces us to think about energy and the approach to energy management. There are two main types of energy sources, fully controllable power plants (nuclear power stations, incineration plants, fossil fuels, biomass, geothermal) and renewable energy sources, which are nondispatchable (wind and solar energy).
The world human population cannot use only renewable energy sources, at least in the near future. The share of renewable energy among other types of energy sources in 2015 is shown in Fig. 1. In the ideal case, renewable energy should cover $100 \%$ of world energy consumption, but it is only a theoretical idea that is not possible to be achieved. We should however increase the proportion of renewable energy sources in the world energy production as fast as possible.

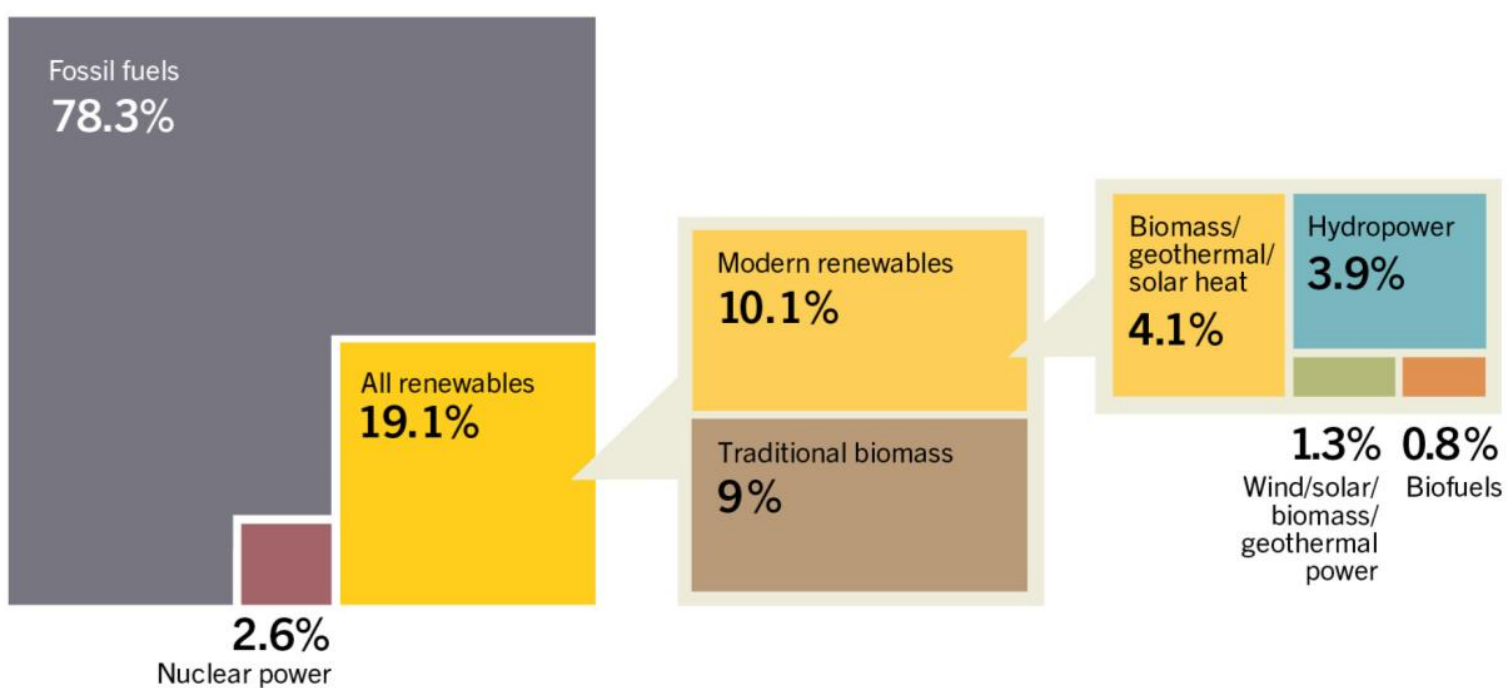

Fig. 1 Estimated renewable energy share of global final energy consumption [1].

Energy from renewable energy sources needs to be (due to its non-dispatchability) stored and used when needed. Energy storage and accumulation is the key part of renewable energy sources utilization. Use of batteries or special hydropower plants is the only way how can we today store the energy from renewable energy sources. There are other experimental alternatives - storing energy in superconducting magnetic energy storage systems (SMES), which store it in a magnetic field created by the flow of current in a superconducting coil that has been cryogenically cooled to a temperature below its superconducting critical temperature. There are also other energy storage systems still in the phase of basic research, so they cannot be considered as regular energy storage systems. Another important step to decreasing pollution and keeping sustainable development of population is reducing emissions produced by combustion engine vehicles and replacing them with electric vehicles. Autonomy electric 
vehicles, which do not have connection to the electrical grid, also need to store electric energy in batteries. Using batteries, especially lithiumion batteries, is a widely discussed and technologically developed topic.

Supercapacitors could be considered as an alternative to conventional batteries for electric vehicles. This paper is related to supercapacitors, it provides their brief description, operation principles, types and recent development.

Electrochemical capacitors, also named supercapacitors or ultracapacitors, are electrical components that are able to store and accommodate certain amounts of energy.

The development of supercapacitors started in the 50 s of the $20^{\text {th }}$ century. First experiments started between 50s and 70s and were conducted by US companies General Electric (GE) and Standard Oil of Ohio (SOHIO). These first electrochemical supercapacitors reached the capacity around $1 \mathrm{~F}$. This type of supercapacitors was patented in 1971 by SOHIO. The first supercapacitor named "Gold Cap" was released to the commercial market in 1982 by Panasonic and had high equivalent series resistance (ESR). In 1982, first electric double-layer capacitor (EDLC) supercapacitor was developed for military purposes by the Pinnacle Research Institute (PRI). This first EDLC supercapacitor already had a low ESR. After ten years, in 1992, Maxwell Laboratories introduced to the commercial market a wide range of EDLC supercapacitors with low ESR named "BoostCap" with nominal capacity of 1 $\mathrm{kF}$. Since 2007, the development of novel hybrid-supercapacitors took place. This kind of supercapacitors should reach higher nominal voltage along with higher volumetric and gravimetric energy density than conventional EDLC supercapacitors. Most of today's supercapacitors have capacity over several thousands Farads and can provide chargedischarge currents in the range from tenths to hundredths of Amperes. Their main advantage from the application point of view is extremely high current (in comparison to batteries) that they are able to operate with. Thanks to this characteristic property, supercapacitors fill the void gap among energy storage devices between batteries (accumulators) and common capacitors (see Fig. 2 below).

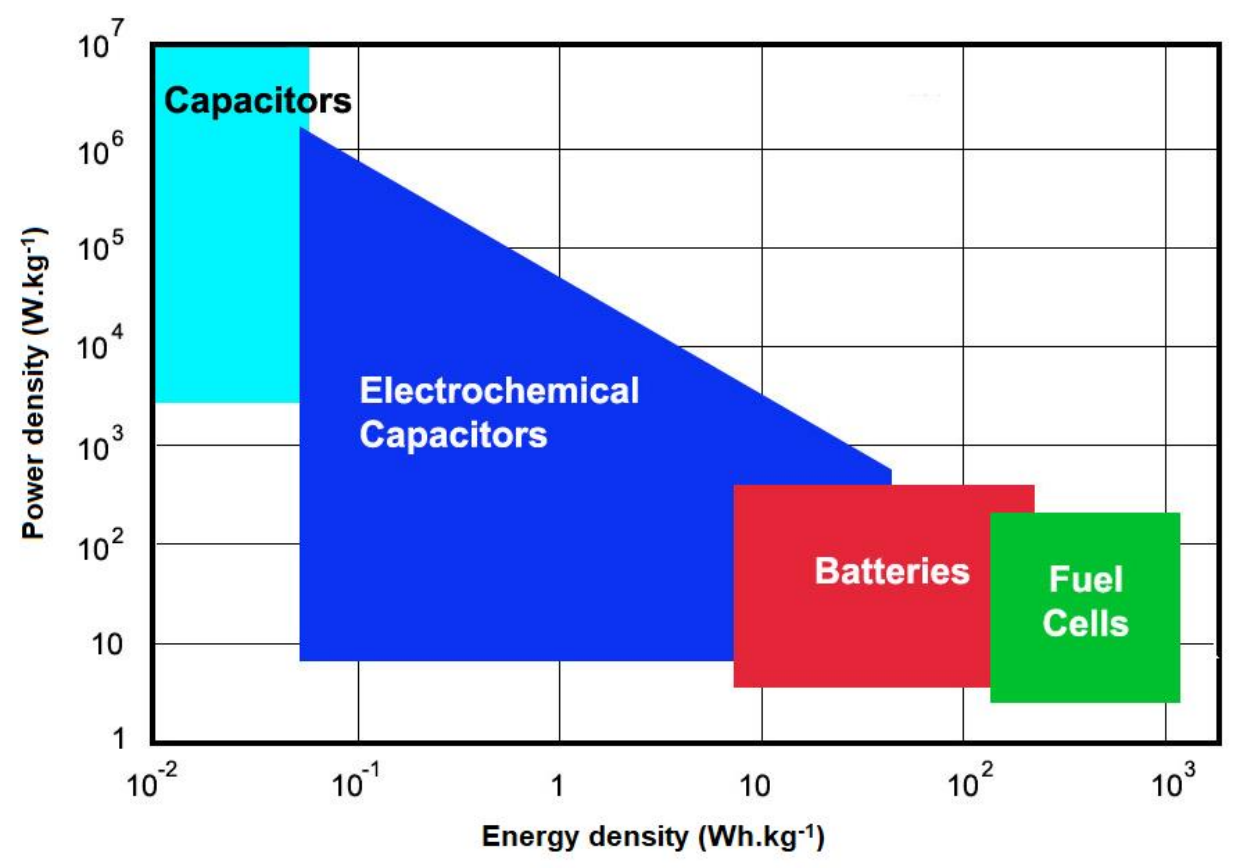

Fig. 2 Ragone chart: Power density as a function of energy density for various energy devices [2]. 
Supercapacitors are used in applications, where is the need to store or release huge amount of energy in a very short time. Nowadays, the supercapacitors are used primarily in Hybrid Electric Vehicles (HEV), Electric Vehicles (EV) and Fuel Cell Vehicles (FCV) like passenger cars, trains, trolleybuses. Another Especially the application of supercapacitors in automotive industry brings many advantages. Supercapacitors can be used to increase the efficiency of hybrid electric vehicles in several ways. Today's hybrid vehicles typically turn off the engine completely when the car stops, and then very efficiently start it again using energy stored in supercapacitors. There are over 600 thousands HEVs that use supercapacitors in their stop-start systems. Some supercapacitor manufacturers designed

\section{Supercapacitor categories and operation principles}

Superconductors can be divided into three basic categories according to the energy storage principle. It should be noted that the supercapacitors belong into the category of wet electrolytic capacitors using a liquid electrolyte that contains ions (charged complexes) to ensure charge transport. The first category includes Electric Double-Layer Capacitors or so-called EDLC Supercapacitors. This type of supercapacitor is the most common type and represents majority on the commercial market. The EDLC supercapacitors use liquid electrolyte. Most of these electrolytes use aprotic solvents like propylene carbonate (PC), diethyl carbonate (DEC), dimethyl carbonate (DME) or ethylene carbonate (EC), which include dissolved salts like tetraethylammonium tetrafluoroborate $\left(\mathrm{TEABF}_{4}\right)$ or lithium hexafluoroarsenate $\left(\mathrm{LiAsF}_{6}\right)$. As electrolytes are used area of supercapacitors' use are electronic devices as Uninterruptible Power Supplies (UPS) and volatile memory backups in PCs. Third area of use are energy harvesting systems, solar arrays or wind turbines, where supercapacitors play a supplementary role next to conventional batteries [1 14$]$. replacements for conventional vehicle batteries using supercapacitors connected across a smaller lead acid battery. The concept of their application is in the moments when the power demand peaks, such as starting a car, and they decrease the overall energy consumption from the batteries. Batteries last much longer when the discharge is small and steady. Supercapacitors in this "hybrid lead-acid battery" configuration essentially smooth out the energy demands on the battery.

(experimentally) ionic liquids as triethylsulfonium bis(trifluoromethylsulfonyl) imide or 1-ethyl-3-methylimdazolium thiocyanate and a wide range of other ionic liquids. These EDLC supercapacitors use electrostatic interaction to accumulate energy in Helmholtz double layers on the phase interface between the surface of the electrodes and the electrolyte. Double-layer capacitance is arising from potential-dependence of the surface energy stored electrostatically at the interface of capacitor electrodes. In this type of supercapacitors, there is no electron exchange and no redox reaction and the energy is stored non-faradaically. The key point to obtain an extremely high capacity is the large surface of the electrodes and the Helmholtz layer thickness. EDLC supercapacitors possess good durability and cycleability in millions of cycles. As an electrode material for EDLC supercapacitors, activated carbon (AC) is widely used, where its large specific surface area is advantageous. 


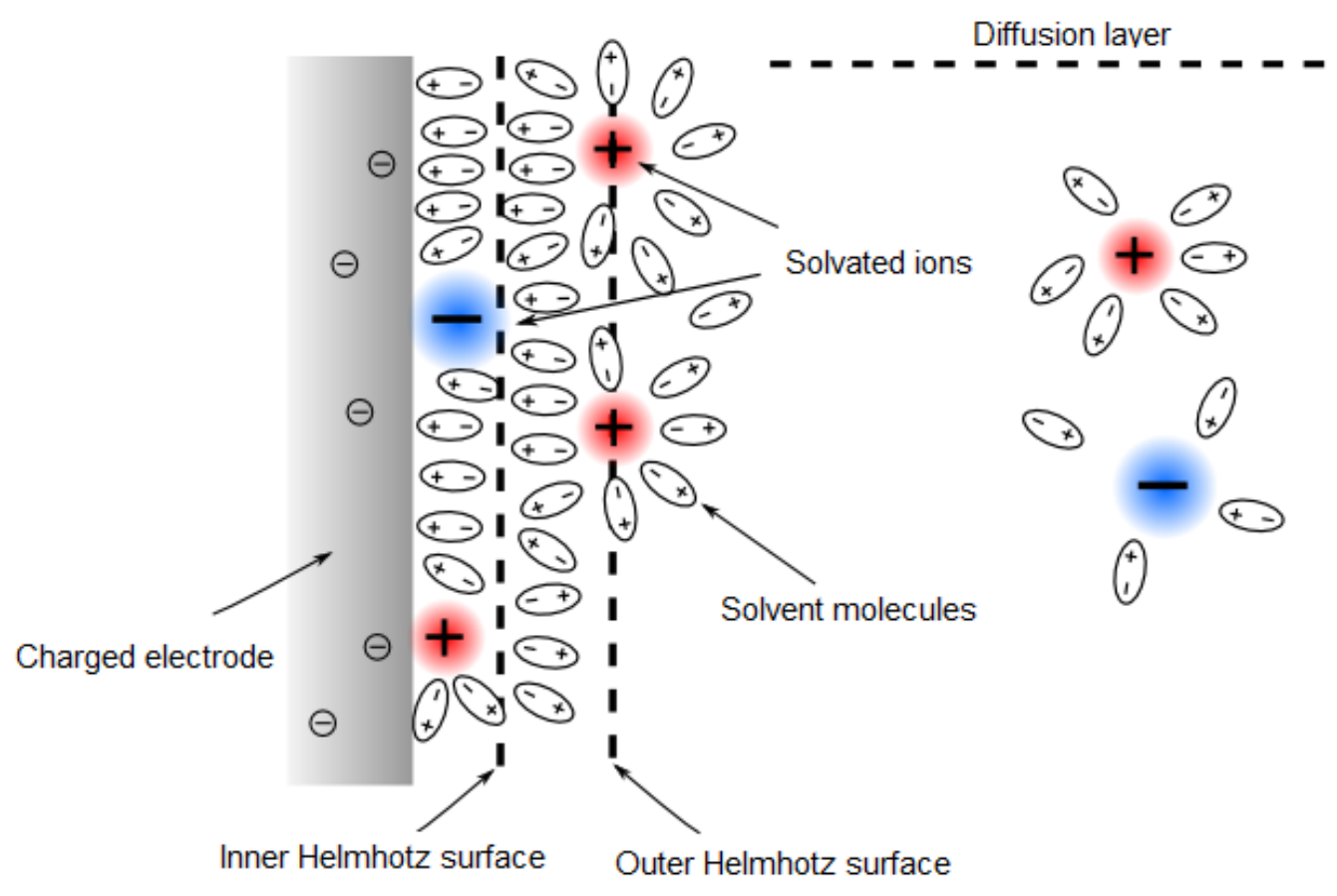

Fig. 3 Diagram of the Helmholtz double layer on a liquid-solid (electrolyte-electrode) interface.

A model of Helmholtz double layer is shown in Fig. 3.

The second category represents so-called pseudo-supercapacitors or faradaic supercapacitors. This kind of supercapacitors is used much less frequently than EDLC supercapacitors and is commercially offered only by a few companies. By operation principle, they are closer to batteries than to capacitors. Pseudocapacitance is a phenomenon, where electrode materials intermediate electron transfer and undergo redox reactions. The pseudocapacitance arises at the electrode surfaces, where faradaic reactions origin, and the reactions involving the passage of energy across the double layer, similar to battery charging or discharging, but capacitance grows due to the special relation that can be expressed as the amount of energy accepted $(\Delta q)$ and the change of potential $(\Delta V)$, so that the derivative $\mathrm{d}(\Delta \mathrm{q}) / \mathrm{d}(\Delta \mathrm{V})$ or $\mathrm{dq} / \mathrm{dV}$ is equivalent to the capacitance $C$. During charge and discharge, there occurs a redox reaction (arising from the bonds in the compounds) and energy transfer between electrolyte and electrode. Energy is not stored in the "dielectric" layer, but is represented by the energy of molecule bonds. The disadvantage of these systems is the principle itself, because during charging and discharging, the electrodes are stressed and degrade faster, compared to the electrostatic storage principle. It is connected with increasing the internal resistance of supercapacitors. Pseudosupercapacitors have both electrodes made by pseudocapacitive materials like ruthenium oxide $\left(\mathrm{RuO}_{2}\right)$ or manganese dioxide $\left(\mathrm{MnO}_{2}\right)$. The stability and cycleability are lower than in the case of EDLC supercapacitors along with lower charging efficiency and longer time response (lower discharge rate).

The third, last type of supercapacitors, is called hybrid supercapacitors. It is the newest type of supercapacitors. This most advanced supercapacitor combines both previous supercapacitor types, the EDLC and pseudo- 
supercapacitors. The main advantage is higher volumetric and gravimetric energy density along with the capability to provide high currents. Due to faradaic reaction that occurs on the negative electrode, which is typically made from pseudocapacitive electrode material, hybrid supercapacitors possess higher energy density. The positive electrode is typically made from activated carbon that stores electrostatic energy in the double layer on the electrode surface. Thanks to the electrostatic interaction between charge carriers and electrode surface on positive electrode side, hybrid supercapacitors can deliver high currents. Hybrid supercapacitors are from the construction and operation point of view close to lithium-ion batteries. Nowadays, there are no hybrid supercapacitors commercially available on the market, but they are investigated in laboratory conditions. Table 1 summarizes and compares supercapacitors with other types of electrochemical energy sources [14-19, 21-33].

Tab. 1 Summarization and comparison of important attributes [1 - 16].

\begin{tabular}{|c|c|c|c|c|}
\hline \multirow{2}{*}{ Attribute } & \multicolumn{3}{|c|}{ Supercapacitor (SC) } & \multirow{2}{*}{$\begin{array}{c}\text { Lithium-ion } \\
\text { battery }\end{array}$} \\
\hline & EDLC SC & Pseudo SC & Hybrid SC & \\
\hline Charge time [s] & $1-10$ & $1-10$ & 100 & 600 \\
\hline Cycle life & 1000000 & 100000 & 500000 & 500 \\
\hline Cell voltage [V] & 2.7 & $2.3-2.8$ & $2.3-2.8$ & 3.6 \\
\hline $\begin{array}{c}\text { Specific energy } \\
{\left[\mathrm{Wh}_{\mathrm{kg}} \mathrm{kg}^{-1}\right]}\end{array}$ & $3-5$ & 10 & 180 & 250 \\
\hline $\begin{array}{c}\text { Cost per kWh } \\
\text { [USD] }\end{array}$ & $\sim 10000$ & $\sim 10000$ & $*$ & $\sim 140$ \\
\hline $\begin{array}{c}\text { Operating } \\
\text { temperature }\left[{ }^{\circ} \mathrm{C}\right]\end{array}$ & $-40-65$ & $-40-65$ & $-40-65$ & $-20-60$ \\
\hline $\begin{array}{l}\text { Self discharge per } \\
\text { month [\%] }\end{array}$ & 60 & 60 & $*$ & 4 \\
\hline $\begin{array}{c}\text { Type of } \\
\text { electrolyte }\end{array}$ & Aprotic or Protic & Protic & Aprotic & Aprotic \\
\hline
\end{tabular}

* Data not available

Electrolytes used in supercapacitors can be divided into two groups - aprotic and protic electrolytes (see Tab. 1 above). Each one has different benefits and limitations. Protic solvents based on water are more environmentally friendly, safe and offer higher conductivity. Aprotic electrolytes increase the working voltage window compared to that of a water soluble electrolyte, hence producing a higher energy density. The most widely used protic electrolyte is potassium hydroxide
$(\mathrm{KOH})$ or sodium hydroxide $(\mathrm{NaOH})$ and sulfuric acid $\left(\mathrm{H}_{2} \mathrm{SO}_{4}\right)$ electrolyte. Among most widely used aprotic electrolytes are lithium salts lithium hexafluorophosphate $\left(\mathrm{LiPF}_{6}\right)$, lithium perchlorate $\left(\mathrm{LiClO}_{4}\right)$ and lithium tetrafluoroborate $\left(\mathrm{LiBF}_{4}\right)$ dissolved in a mixture of solvents such as dimethyl carbonate (DMC), diethyl carbonate (DEC) and ethylene carbonate (EC). The protic electrolytes possess higher conductivity, they exhibit higher fire safety, lower price and are more 
environmentally friendly than the aprotic ones.

On the other side the protic solvents possess, significantly narrower working potential window.

\section{Conclusions}

Supercapacitors represent an interesting alternative to conventional batteries. There are new types of hybrid supercapacitors based on the established lithium-ion technology. These hybrid lithium-ion supercapacitors already have a higher energy density. Today, these hybrid lithium-ion supercapacitors can find use in applications, where only conventional lithiumion batteries were used so far. The use of supercapacitors in many applications was limited by their low energy density and high price (SC \$10 $000 \mathrm{kWh}$, Li-ion $\$ 240 \mathrm{kWh}$ ). New generation of supercapacitors possess a similar energy and power density (EDLC SC 6 Wh.kg-1 Li-ion 250 Wh.kg ${ }^{-1}$, Hybrid SC around $180 \mathrm{Wh} \cdot \mathrm{kg}^{-1}$ ) as lithium-ion batteries and are able to deliver considerably higher currents than lithium-ion batteries [30].

As a follow-up on this issue, we are performing a series of experiments dealing with hybrid lithium-ion supercapacitors based on our experience in the field of lithium-ion batteries, especially the pre-lithiation method, which is a very important element in the hybrid lithiumion supercapacitor technology.

\section{Acknowledgment}

This work was supported by the project of the Centre for Research and Utilization of Renewable Energy under project No. LO1210 - "Energy for Sustainable Development (ENPUR)" reg. No. 0398.

\section{References}

[1] Renewables Global Status Report (REN21), http://www.ren21.net/wpcontent/uploads/2 017/06/178399_GSR_2017_Full_Report_0 621_Opt.pdf (access 17.11.2017), Global Status Report (2015) 42.

[2] J. B. Goodenough, H. D. Abruna, M. V. Buchanan, Report of the Basic Energy Sciences Workshop on Electrical Energy Storage (2007) 1-21, DOI: 10.2172/935429.

[3] L. Nègre, B. Daffos, P.L. Taberna and P. Simon, Journal of Electrochem. Society, 162(5) (2015) A5037-A5040, DOI: 10.1149/2.0061505jes.

[4] P. Dvorak, Materials for Supercapacitors dissertation thesis, Brno University of Technology, (2014) 82.

[5] J. Zhang, H. Wu, J. Wang, J. Shi, Z. Shi, Electrochimica Acta, 182 (2015) 156-164.

[6] S. Zhang, Journal of Power Sources, 343 (2017) 322-328.

[7] B. E. Conway, Electrochemical Supercapacitors, Springer US, New York, 1999.

[8] J. Miller, P. Simon, Journal of the Electrochemical Society, 17(1) (2008) 3132.

[9] K. Naoi, M. Morita, Journal of the Electrochemical Society, 17(1) (2008) 4448.

[10] A. Shukla, A. Banerjee, M. Ravikumar and A. Jalajakshi, Electrochimica Acta, 84 (2012) 165-173.

[11] Y. Zhang, H. Feng, X. Wu, L. Wang, A. Zhang, T. Xia, H. Dong, X. Li and L. Zhang, International Journal of Hydrogen Energy, 34 (2009) 4889-4899.

[12] G. Yu, X. Xie, L. Pan, Z. Bao and Y. Cui, Nano Energy, 2 (2013) 213-234.

[13] Y.-P. Lin, N.-L. Wu, Journal of Power Sources, 196(2) (2011) 851-854.

[14] C. Arbizzani, M. Mastragostino and L. Meneghello, Electrochimica Acta, 40 (1995), 2223-2228.

[15] C. Lei, F. Markoulidis, Z. Ashitaka, C. Lekakou, Electrochimica Acta, 92 (2013) 183-187. 
[16] J. Dai, K. Fu, R. Palanisamy, A. Gong, G. Pastel, R. Kornfeld, H. Zhu, M. Sanghadasa, E. Bekyarova and L. Hu, Journal of Materials Chemistry A, 5 (2017) 15266-15272.

[17] J. Sun, Y. Huang, Y. N. S. Sea, Qi Xue, Z. Wang, M. Zhu, H. Li, X. Tao, Ch. Zhi, H. Hu, Materials Today Energy, 5 (2017) $1-14$

[18] Y. Liu, X. Peng, Applied Materials Today, 8 (2017) 104-115.

[19] A. Eftekhar, Energy Storage Materials, 9 (2017) 47-69.

[20] M. Ceraolo, G. Lutzemberger, D. Poli, Journal of Energy Storage, 11 (2017) 211218.

[21] D. Qu, X. Feng, X. Wei, L. Guo, H. Cai, H. Tang, Z. Xie, Applied Surface Science, 413 (2017) 344-350.

[22] A. M. Elshahawy, C. Guan, X. Li, H. Zhang, Y. Hu, H. Wu, S. J. Pennycook, J. Wang, Nano Energy, 39 (2017) 162-171.

[23] S. Makino, R. Yamamoto, S. Sugimoto, W. Sugimoto, Journal of Power Sources, 326 (2016) 711-716.

[24] S. Kim, J. Lee, J. Soo Kang, K. Jo, S. Kim, Y.-E. Sung, J. Yoon, Chemosphere, 125 (2015) 50-56.

[25] S. S.Zhang, Journal of Power Sources, 343 (2017) 322-328.

[26] J. Zhanga, Z. Shia, C. Wang, Electrochimica Acta, 125 (2014) 22-28.

[27] J. Zhang, H. Wu, J. Wang, J. Shi, Z. Shi, Electrochimica Acta, 182 (2015) 156-164.

[28] G. Gourdin, P. H. Smith, T. Jiang, T. N. Tran, D.Qu, Journal of the Electroanalytical Chemistry, 688 (2013) 103-112.

[29] N. S. Hudak, A. D. Schlichting, K. Eisenbeiser, Journal of Electrochemical Society, 164(4) (2017) A691-A700.

[30] R. Attias, D. Malka, A. Borenstein, O. Hana, S. Luski and Doron Aurbach, Journal of Electrochemical Society, 164(9) (2017) A2231-A2237.
[31] Battery University, http://www. http://batteryuniversity.com (access 17.11.2017), Article: BU-209, (2017).

[32] T. Broussea, D. Bélanger, J. W. Long, Journal of Electrochem. Society, 162(5) (2015) A5185-A5189, DOI: 10.1149/2.0201505jes.

[33] V. Sedlakova, J. Sikula, J. Majzner, P. Sedlak, T. Kuparowitz, B. Buergler, P. Vasina, Journal of Power Sources, 286 (2015) 58-65, DOI: 10.1016/j.jpowsour.2015.03.122. 